\title{
ON A HINGED PLATE EQUATION OF NONCONSTANT THICKNESS
}

\author{
CRISTIAN-PAUl DANET
}

Abstract. This note is concerned with the problem of existence and uniqueness of solutions for a fourth order boundary value problem that models the deflection of a hinged plate of nonconstant thickness.

Mathematics subject classification (2010): 35J35, 35J40, 74K20.

Keywords and phrases: Fourth order, plate theory.

\section{REFERENCES}

[1] M. S. Berger, Nonlinearity and Functional Analysis. Lectures on Nonlinear Problems in Mathematical Analysis, Academic Press, 1977.

[2] D. Buoso, P. LAmberti, Shape deformation for vibrating hinged plates, Math. Methods Appl. Sci. 37, 2 (2014), 237-244.

[3] C.-P. DANET, Two maximum principles for a nonlinear fourth order equation from thin plate theory, Electron. J. Qual. Theory Differ. Equ. 31, (2014), 1-9.

[4] F. Gazolla, H.-C. Grunau, G. Sweers, Polyharmonic Boundary Value Problems, Springer Verlag, 2010.

[5] D. Gilbarg and N. S. Trudinger, Elliptic Partial Differential Equations of Second Order, Springer Verlag, 2001.

[6] O. A. LadyZhenskaya, The Mathematical Theory of Viscous Incompressible Flow, Gordon and Breach Science Publishers, 1969.

[7] S. A. NaZarov, A. Stylianou, G. Sweers, Hinged and supported plates with corners, Z. Angew. Math. Phys. 63, 5 (2012), 929-960.

[8] S. A. NaZArov, G. Sweers, A hinged plate equation and iterated Dirichlet Laplace operator on domains with concave corners, J. Differential Equations 233, 1 (2007), 151-180.

[9] E. PARINI, A. STYLIANOU, On the positivity preserving property of hinged plates, SIAM J. Math. Anal. 41, 5 (2009), 2031-2037. 